\title{
Timing of Nutrient Termination and Reapplication for Growth, Flower Initiation, and Flowering of the Nobile Dendrobium Orchid
}

\author{
Christine Yung-Ting Yen ${ }^{1}$ and Terri W. Starman ${ }^{2,6}$ \\ Department of Horticultural Sciences, Texas A\&M University, 2133 TAMU, College Station, TX \\ 77843-2133
}

\author{
Yin-Tung Wang ${ }^{3,5}$ \\ Department of Horticultural Sciences, Texas A\&M University System, Texas AgriLife Research and \\ Extension Center at Weslaco, 2415 East Highway 83, Weslaco, TX 78596
}

\author{
Andreas Holzenburg ${ }^{3}$ \\ Microscopy and Imaging Center, 2257 TAMU, and Department of Biology, 3258 TAMU, Texas A\&M \\ University, College Station, TX 77843 \\ Genhua Niu ${ }^{4}$ \\ Department of Horticultural Sciences, Texas AgriLife Research and Extension Center at El Paso, \\ 1380 A\&M Circle, El Paso, TX 79927
}

\begin{abstract}
AdDitional INDEX wORDs. Dendrobium nobile, mineral nutrition, flower differentiation, histology, floral primordium
Abstract. Hybrids of Dendrobium nobile Lindl. have high potential to become a high-value pot plant, but detailed research to support the development of commercial production protocols was lacking. A $3 \times 5$ factorial experiment was conducted to investigate the effects of nutrient termination date (1 Aug., 1 Sept., or 1 Oct.) and nutrient reapplication time (at the beginning or in the middle of cooling, immediately after or 2 weeks after the completion of cooling, or no nutrient reapplication) on growth and flower development of Dendrobium Sea Mary 'Snow King,' a $D$. nobile hybrid. Interaction between nutrient termination date and reapplication time on growth and flowering was nonsignificant for all variables measured, and reapplication time had only a minor effect on leaves remaining. Regardless of nutrient reapplication time, delaying nutrient termination date resulted in improved growth and flowering. Nutrient termination on 1 Oct. resulted in taller plants with more nodes, leaves remaining, flowering nodes, and total flowers as well as fewer aborted flowers than an earlier termination date. Nutrient supply until 1 Oct. did not lead to differences in time required for anthesis but extended the time needed to reach full flowering by $1.5 \mathrm{~d}$. The results suggest that flower development benefited more from the nutrients that were accumulated in mature pseudobulbs before nutrient termination rather than from those being taken from the reapplied fertilizers. Only lateral buds protruding $2 \mathrm{~mm}$ or more from the pseudobulb surface showed differentiated floral structures when examined histologically. The buds, excised 4 weeks after cooling treatments began, showed that nutrient termination on 1 Aug. resulted in larger flower primordia than those ended on 1 Oct., indicating an earlier or faster flower differentiation with earlier nutrient termination. No aerial shoot formation or reversion of reproductive to vegetative buds arose as a result of either late nutrient termination or resumption of nutrient application.
\end{abstract}

Orchids have long been attractive plants to many people because of their wide variety of shapes and patterns, exotic colors, long-lasting flowers, and fragrance. The U.S. Department of Agriculture (USDA) reported that in the United States, the wholesale value of potted orchids increased from $\$ 47$ million in 1996 to $\$ 144$ million in 2005 (USDA, 2006). Dendrobium Sw. was reported to be the second most valued orchid genus sold in Japan in 2002, which had a market share of

Received for publication 17 Mar. 2008. Accepted for publication 19 May 2008. We thank E. Ann Ellis for developing the histological protocol and assistance and the Fred C. Gloeckner Foundation, Norman Fang and his family, and the American Orchid Society for funding the project.

${ }^{1}$ Graduate Research Assistant.

${ }^{2}$ Associate Professor.

${ }^{3}$ Professor.

${ }^{4}$ Assistant Professor.

${ }^{5}$ Current address: Matsui Nursery, Salinas, CA.

${ }^{6}$ Corresponding author. E-mail: tstarman@tamu.edu.
20\%, only behind Phalaenopsis Blume (Laws, 2004; Wang, 2004). Dendrobium has also been reported to be the most economically important flowering pot orchid genus sold in Hawaii with a wholesale value of \$6 million in both 2005 and 2006 (USDA, 2007).

Dendrobium nobile is one of the most commonly cultivated Dendrobium species (Baker and Baker, 1996) that has been grown for decades. It is native to habitats ranging from the Himalayas to southeast Asia and much of southern China. This sympodial epiphyte produces lateral flower buds (Baker and Baker, 1996). Flowers open nearly simultaneously from leaf nodes of the long pseudobulbs that matured the previous year (Ichihashi, 1997; Rotor, 1952, 1959; Wood, 2006).

Although D. nobile has been grown for years, its hybrids, the nobile dendrobiums, are relatively new commercially massproduced orchids having a high market potential. Commercial growers are recommended to apply nutrients to 1-year-old nobile dendrobium liners soon after they have been planted in 
February, then reduce the rate or stop applying mineral nutrients completely in late July or August to "avoid potential flower buds turning into aerial shoots" (Yamamoto Dendrobiums, 2007). In a commercial nursery, mature plants that produce aerial shoots instead of flowers are unmarketable and become a total financial loss to the grower. Wood (2006) recommended withholding nitrogen after 1 Aug. in the northern hemisphere for D. nobile and its hybrids. Baker and Baker (1996) suggested reducing watering after new growth matures in autumn and withholding nutrients until the next spring. However, none of these claims were supported by solid research data or explained the cause and effect in detail.

Bichsel et al. (2008) investigated how various rates of nitrogen $(\mathrm{N})$, phosphorus $(\mathrm{P})$, or potassium $(\mathrm{K})$ and nutrient termination dates (1 Sept., 1 Oct., or 1 Nov. 2005) affected growth and flowering of Dendrobium Red Emperor 'Prince' in a warm climate. It was found that ending nutrient application on 1 Oct. resulted in the best vegetative and reproductive characteristics. Plants were taller with more nodes, leaves, and flowers when nutrient application was ended on 1 Oct. than 1 Sept. or 1 Nov. regardless of $P$ rates. Plants produced more flowers with 1 Oct. nutrient termination than the earlier or later date when given $0.1 \mathrm{~g} \cdot \mathrm{L}^{-1} \mathrm{~N}$. However, when $\mathrm{N}$ rate was 0.2 or $0.4 \mathrm{~g} \cdot \mathrm{L}^{-1}$, more flowers were produced at 1 Sept. or 1 Oct. than the later nutrient termination date. Plants with all $\mathrm{N}$ rates and nutrient termination dates took similar time to reach anthesis, except for a delay when ending nutrients containing 0.2 or $0.4 \mathrm{~g} \cdot \mathrm{L}^{-1} \mathrm{~N}$ on 1 Nov.

Optimum timing of nutrient termination for quality flowering varies with orchid genera. For the cultivar Pendragon Sikkim of a Cymbidium Sw. hybrid, nutrient application was suggested to be ended before flower initiation began for increased inflorescence/shoot ratio along with earlier flowering (Arnold Bik and van den Berg, 1983). For Phalaenopsis TAM Butterfly, maintaining $\mathrm{N}$ fertilization until the completion of flower initiation increased flower number (Wang, 2000). The best time to end nutrient application in nobile dendrobiums remains to be defined.

After flower initiation in orchids, resumption of nutrient supply may be needed for optimum flower development because reproductive growth may represent a strong nutrient sink. However, nutrient reapplication might cause detrimental aerial shoot formation or reversion of floral primordia to vegetative shoots. The most ideal stage of development for nutrient reapplication still needs to be defined. To observe if the bud reversion occurs in nobile dendrobiums, it is necessary to know when an initiated floral bud is distinguishable under a microscope and to identify histological differences between vegetative and reproductive primordia.

The objectives of this study were to investigate the effect of nutrient termination date and reapplication time on growth and flowering, to study the development of axillary buds by histological examination, and to ascertain if nutrient reapplication would cause aerial shoot formation or reversion of reproductive to vegetative buds.

\section{Materials and Methods}

Plant material and growing conditions. One-year-old liners of Dendrobium Sea Mary 'Snow King,' a D. nobile hybrid, propagated from single-node cuttings and planted in sphagnum moss with an average pseudobulb (i.e., a thickened portion of the stem in orchids functioning as a storage organ for water and nutrients) height of 7 to $10 \mathrm{~cm}$, were shipped from Yamamoto Dendrobiums in Mountain View, HI. Plants arrived at Texas A\&M University, College Station, on 15 Feb. 2006 and were potted into $10.2-\mathrm{cm}$ (top diameter, 414- $\mathrm{mL}$ volume) standard green plastic pots on 16 to $18 \mathrm{Feb}$. and placed in a glass-wall and polycarbonate-roof greenhouse. The root substrate consisted of two parts of coarse peat (Sunshine Peat; Sun Gro Horticulture, Bellevue, WA), one part coarse perlite, and one part No. 3 grade diatomite (Diatomite USA, Elma, NY), amended with powdered Micromax (Scotts, Marysville, $\mathrm{OH}$ ) at $1 \mathrm{~g} \cdot \mathrm{L}^{-1}$ as a source of micronutrients and powdered dolomitic limestone at $5 \mathrm{~g} \cdot \mathrm{L}^{-1}$. A wetting agent, Aqua Gro $2000 \mathrm{G}$ (Scotts), was added to the medium at $0.5 \mathrm{~g} \cdot \mathrm{L}^{-1}$.

Plants were potted with the root substrate packed tightly to secure them in place when lifted up only by the upper portion of the pseudobulbs. Immediately after potting, plants were irrigated with reverse osmosis (RO) water containing fungicides [etridiazole and thiophanate-methyl (Banrot 40\% WP; Scotts)] at $0.6 \mathrm{~g} \cdot \mathrm{L}^{-1}$ to prevent root rot. Then, pots were irrigated as needed with a nutrient solution made with $\mathrm{RO}$ water and a $15 \mathrm{~N}-$ 2.2P-12.5K (Peters Excel 15-5-15 Cal-Mag; Scotts) watersoluble fertilizer at $0.67 \mathrm{~g} \cdot \mathrm{L}^{-1}$. The nutrient termination dates were 1 Aug., 1 Sept., and 1 Oct. 2006. Plain RO water was used after nutrient application was ended. The five nutrient reapplication times were at the beginning of cooling (time 1), in the middle of cooling (time 2), immediately after cooling (time 3 ), 2 weeks after the completion of cooling (time 4), and no nutrient reapplication (time 5).

Plants were spaced pot-to-pot in $30.8 \times 51.4-\mathrm{cm}$ molded black plastic carrying trays [4.00 Transport Tray (15); Landmark Plastic Corp., Akron, $\mathrm{OH}]$ on the greenhouse bench with leaves orienting east and west to best capture sunlight. The pseudobulbs were supported with bamboo stakes (Bamboo Supply, Lakeland, FL) and twist ties to minimize lodging and mutual shading. Whenever an undesirable second new shoot emerged, it was removed to maintain a single pseudobulb per pot.

Greenhouse irradiance and air temperature at plant canopy level were recorded hourly with data loggers [HOBO (Onset Computer Co., Bourne, MA), WatchDog (Spectrum Technologies, Plainfield, IL), and Apogee line quantum sensors (Apogee Instruments, Logan, UT)] (Fig. 1). Plants were grown

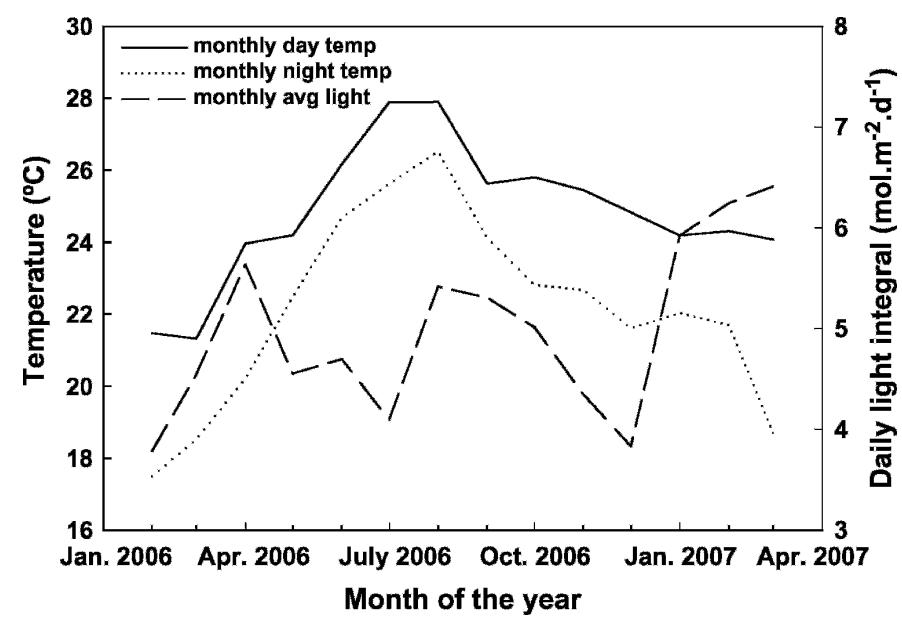

Fig. 1. Average monthly light and air temperature in the greenhouse throughout the experimental period. 
in a warm environment (average $25.3{ }^{\circ} \mathrm{C}$ day $/ 23.0{ }^{\circ} \mathrm{C}$ night) under an average $4.9 \mathrm{~mol} \cdot \mathrm{m}^{-2} \cdot \mathrm{d}^{-1}$ daily light integral until the pseudobulbs matured. Pesticides [Bacillus thuringiensis Berliner (Gnatrol; Valent BioSciences, Libertyville, IL), azadirachtin (Azatin; OHP, Mainland, PA), cyfluthrin (Decathlon; $\mathrm{OHP}$ ), and imidacloprid (Marathon II; OHP)] were applied when necessary to control fungus gnats (Bradysia coprophila Lintner), caterpillars (Trichoplusia ni Hubner), and mealy bugs (Planococcus citri Risso).

Plants were subjected to a 6-week cooling treatment at $15^{\circ} \mathrm{C}$ in a growth chamber for flower initiation starting on 13 Nov. 2006. The growth chamber was maintained at $65 \%$ relative humidity and a 12 -h photoperiod with $350 \mu \mathrm{mol} \cdot \mathrm{m}^{-2} \cdot \mathrm{s}^{-1}$ photosynthetic photon flux provided by both fluorescent and incandescent lamps. The average air temperature recorded was $14.5 \pm 0.35{ }^{\circ} \mathrm{C}$. Plants were moved back to the warm greenhouse with temperatures averaging $24.3{ }^{\circ} \mathrm{C}$ day $/ 21.9{ }^{\circ} \mathrm{C}$ night after the completion of cooling for flower development. The average daily light integral from the end of cooling until full flowering was $6.1 \mathrm{~mol} \cdot \mathrm{m}^{-2} \cdot \mathrm{d}^{-1}$.

EXPERIMENTAL DESIGN. The experiment was a $3 \times 5$ factorial with three nutrient termination dates and five nutrient reapplication times. A randomized complete block design with 12 replications was used. A single plant in a pot constituted an experimental unit. A total of 180 vegetatively propagated nobile dendrobium plants were used. Twelve separate plants served as an observational control group (i.e., not included in statistical analysis) and continued receiving nutrients at 0.67 $\mathrm{g} \cdot \mathrm{L}^{-1}\left(100 \mathrm{mg} \cdot \mathrm{L}^{-1} \mathrm{~N}\right)$ throughout the experimental period and remained in the greenhouse without cooling.

Data Collection. Data including plant height (measured from the medium surface to the tip of the pseudobulb), pseudobulb width (the diameter of the widest point from side to side) and thickness (the diameter of the thickest point from front to back), time to anthesis (the first flower bud on a plant cracked to open), time to full flowering (all flowers on a plant fully opened), flower diameter (from the margin of the left petal to that of the right petal), number of nodes, remaining leaves on the pseudobulb before anthesis, aerial shoots, aborted buds, flowering nodes, and total flowers were collected. For the two variables, time to anthesis and full flowering, the number of days were recorded from the time of plants being removed from the cooling treatments. Flower diameter was determined by averaging those of two flowers, one on each of the two middle nodes of a pseudobulb. Average flower number per flowering node was calculated by dividing total flower number by flowering node number.

STATISTICAL ANALYSIS. All data except for those from the observational control group were subjected to analysis of variance and Duncan's multiple range test was used for comparing the means at $P \leq 0.05$. Percentage data were arcsine-transformed to normalize distribution of variance before subjected to statistical analysis. All analysis was performed using SAS (version 9.1.3; SAS Institute, Cary, NC).

Histology. For each treatment and control group, two plants were randomly selected when lateral buds started to swell. Buds protruding $2 \mathrm{~mm}$ from the pseudobulb epidermis were sampled to study the histological changes and to determine the possible interconversion between vegetative and reproductive buds. All microscopic studies were performed using a new method developed at the Microscopy and Imaging Center, Texas A\&M University, College Station.
One of the middle lateral buds on each selected plant was excised from the pseudobulb. The outer bracts of the buds were removed under water using a dissecting microscope without damaging the bud primordia. Tissues were then transferred into freshly prepared fixative. Every $10 \mathrm{~mL}$ of the fixative was made by mixing $2.5 \mathrm{~mL}$ formaldehyde solution (heating $0.8 \mathrm{~g}$ paraformaldehyde in $10 \mathrm{~mL}$ of distilled water and a pellet of $\mathrm{NaOH}$ in a flask until the solution cleared and allowed to cool), $5 \mathrm{~mL}$ $0.2 \mathrm{M}$ phosphate buffer (mixing $72 \mathrm{~mL}$ of $0.2 \mathrm{M} \mathrm{Na}_{2} \mathrm{HPO}_{4}$ and $28 \mathrm{~mL}$ of $\left.0.2 \mathrm{M} \mathrm{NaH}_{2} \mathrm{PO}_{4}, \mathrm{pH} 7.2\right), 0.5 \mathrm{~mL} 50 \%(\mathrm{w} / \mathrm{v})$ glutaraldehyde, $0.15 \mathrm{~mL}$ dimethyl sulfoxide, and $1.85 \mathrm{~mL}$ distilled water. The tissues in the fixative were put under vacuum for $1 \mathrm{~min}$ to remove air from the tissues and expedite the penetration of the fixative.

After sitting at room temperature for $30 \mathrm{~min}$, the tissues were cold-microwaved for 6 min with a 30-s on-and-off vacuum cycle at $178-\mathrm{W}$ power and $20^{\circ} \mathrm{C}$ by using the PELCO BioWave Pro Laboratory Tissue Processing System (Ted Pella, Redding, CA) that was equipped with the ColdSpotT temperature control system (Ted Pella). Then, the fixative was replaced by a phosphate buffer and microwaved with a setting of 30 -s onand-off vacuum cycle for $1 \mathrm{~min}$ at $250-\mathrm{W}$ power and $20^{\circ} \mathrm{C}$. The setting was used thereafter when microwave assistance was needed. The phosphate buffer was replaced again and the microwave treatment was repeated for a total of four buffer washes. The buffer was decanted and 1\% (w/v) osmium tetroxide aqueous solution was added for postfixation. Then, a 1-min microwaving was applied to the specimens before the Eppendorf vials were sealed with parafilm and placed at $4{ }^{\circ} \mathrm{C}$ overnight.

The next day, the osmium tetroxide solution was decanted and water was added for a rinse. The methanol/water dehydration series at 5\% methanol v/v increments (from 5\% to 95\%) was used by substitution with the next graded methanol/water solution followed by a 1-min microwaving treatment. After the $95 \%$ methanol step, three consecutive steps with $100 \%$ methanol were performed. The tissues were then transferred to glass vials, immersed in propylene oxide under a chemical hood, and placed on a rotator while preparing resin mixture for infiltration.

Every $10 \mathrm{~g}$ (excluding the weight of DER 736 resin and BDMA) resin mixture was made by fully mixing $2.18 \mathrm{~g}$ ERL 4221 resin, 1.39 g Quetol 651 resin, 1.43g DER 736 resin, $6.43 \mathrm{~g}$ nonenyl succinic anhydride, and $0.2 \mathrm{~mL}$ benzyldimethylamine (BDMA) in order. A volume of the resin mixture was added to the sample vials to have $50 \%(\mathrm{v} / \mathrm{v})$ resin concentration and placed on a rotator for $2 \mathrm{~h}$. Another volume of resin was then added to give $75 \%$ resin concentration and left rotating overnight. The next day, the tissues were put under vacuum for $1 \mathrm{~min}$. Propylene oxide/resin mixture was replaced with newly mixed resin, and sample vials were rotated overnight. Vacuum and replacement of newly mixed resin for rotating overnight were repeated four times. Then, a last batch of resin was mixed for embedding. Specimens were transferred into molds in the desired orientation, and the molds were filled up with resin mixture. Molds were placed in an incubator at $55^{\circ} \mathrm{C}$ overnight for resin polymerization. After the molds were removed from the incubator to cool the next day, the polymerized resin blocks were ready for sectioning.

Longitudinal sections of bud primordia were cut at $\approx 0.5 \mu \mathrm{m}$ thickness by using the Reichert Ultracut microtome (Leica Microsystems, Wetzlar, Germany) with glass knives, mounted 
on glass slides, stained with aqueous toluidine blue-borax solution (both $1 \%, \mathrm{w} / \mathrm{v}$ ) for the visualization of histology, and examined under a Zeiss Axiophot light microscope (Carl Zeiss, Oberkochen, Germany) with brightfield illumination to determine if reproductive or vegetative primordia had developed. Images were acquired by a monochrome CCD camera (DXM 1200; Nikon, Melville, NY) and processed using the MetaVue 7 imaging system (Molecular Devices, Sunnyvale, CA) and Image J 1.37 image processing and analysis routines (Abramoff et al., 2004). Images were contrast-enhanced and sharpened when needed.

\section{Results}

Interaction between nutrient termination date and reapplication time on growth and flowering of Dendrobium Sea Mary 'Snow King' was nonsignificant. Nutrient termination date had more impact on vegetative parameters than reapplication time, which only affected leaves remaining. Plants were taller with more nodes when nutrient application was ended on 1 Oct. than 1 Sept. with no differences between 1 Aug. and the other treatments (Table 1). Nutrient termination on 1 Oct. resulted in at least one more leaf remaining ( $82 \%$ leaf retention) on pseudobulbs than those being ended of nutrients on 1 Aug. or 1 Sept. (as low as 74\% leaf retention). On the other hand, plants had higher leaf retention when nutrient application resumed at the beginning of cooling $(82 \%)$ or immediately after cooling $(80 \%)$ than at other reapplication times $(76 \%)$, but no prominent consistent trend was found among the five nutrient reapplication times. None of the treatments resulted in differences in pseudobulb width and thickness and the formation of aerial shoots. Pseudobulbs were $2.3 \mathrm{~cm}$ wide and $1.8 \mathrm{~cm}$ thick on average.

Flowering among nutrient termination and reapplication treatments were not different by visual observation. Nearly all plants started to flower simultaneously on 26 Jan. 2007 and they were in full flowering within 1 week. Nutrient termination date did not lead to differences in time required for anthesis after the completion of cooling treatment, whereas prolonged nutrient supply in the previous year extended the time that plants needed to reach full flowering after cooling (Fig. 2). Plants that were ended nutrient application on 1 Oct. took 1.5 $\mathrm{d}$ more to reach full flowering compared with those ended of nutrients on 1 Aug., resulting in slightly less uniform flowering.

Except for the slightly slower flower development from anthesis to full flowering, flower quality was improved by prolonged nutrient supply with more flowering nodes, more

Table 1. Effect of nutrient termination date regardless of nutrient reapplication time on plant height, node number, and leaves remaining of Dendrobium Sea Mary 'Snow King'.

\begin{tabular}{lcccc}
\hline $\begin{array}{l}\text { Nutrient } \\
\text { termination } \\
\text { date }\end{array}$ & $\begin{array}{c}\text { Plant ht } \\
(\mathrm{cm})\end{array}$ & $\begin{array}{c}\text { Nodes } \\
(\text { no. })\end{array}$ & \multicolumn{2}{c}{ Leaves remaining } \\
\hline 1 Aug. & $27.9 \mathrm{ab}^{\mathrm{z}}$ & $11.1 \mathrm{ab}$ & $8.1 \mathrm{~b}$ & $73.5 \mathrm{c}$ \\
1 Sept. & $26.5 \mathrm{~b}$ & $10.7 \mathrm{~b}$ & $8.3 \mathrm{~b}$ & $77.5 \mathrm{~b}$ \\
1 Oct. & $28.5 \mathrm{a}$ & $11.5 \mathrm{a}$ & $9.5 \mathrm{a}$ & $82.2 \mathrm{a}$ \\
Significance & $*$ & $* *$ & $* * *$ & $* * *$
\end{tabular}

${ }^{\mathrm{z}}$ Mean separation within columns by Duncan's multiple range test at $P \leq 0.05$.

${ }^{*,}, * *, * * *$ Significant at $P \leq 0.05,0.01$, or 0.001 , respectively.

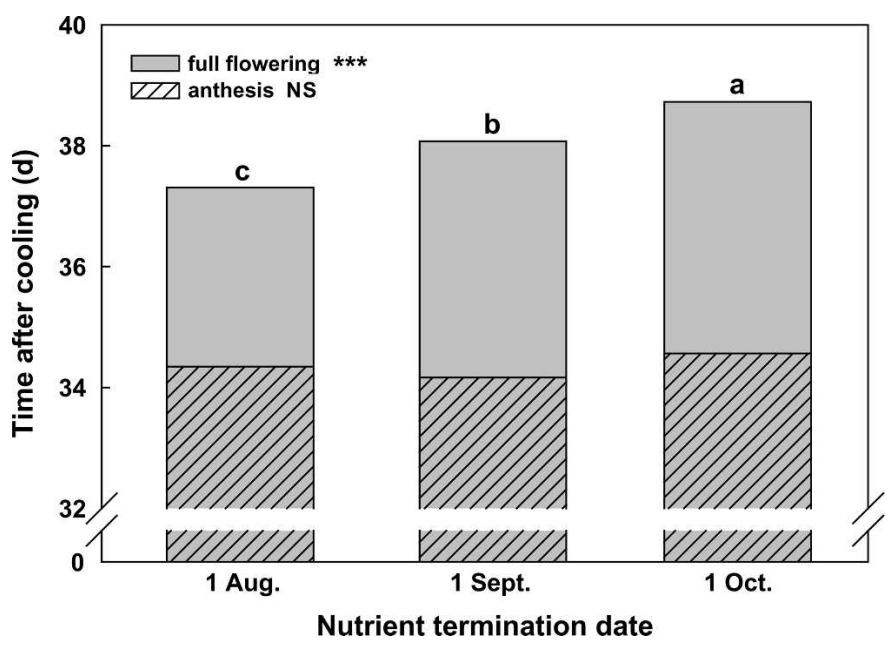

Fig. 2. Effect of nutrient termination date regardless of nutrient reapplication time on time required to reach anthesis and full flowering after cooling treatment in Dendrobium Sea Mary 'Snow King.' NS, ${ }^{* * *}$ Nonsignificant or significant at $P \leq 0.001$. Means with different letters are significantly different by Duncan's multiple range test at $P \leq 0.05$.

total flower number, and fewer aborted floral buds on a plant (Table 2). Plants that received nutrients until 1 Sept. or 1 Oct. had more flowers on each flowering node than those that received nutrients until 1 Aug.

Flower diameter was unaffected by nutrient termination date. Plants without nutrient reapplication produced bigger flowers $(6.5 \mathrm{~cm})$ than plants receiving nutrients at the beginning of or 2 weeks after cooling $(6.2 \mathrm{~cm})$. However, time of reapplying nutrients had limited visual effect on flower diameter.

Whether or not a plant had been exposed to cooling, flower differentiation was not observed in axillary buds until they protruded $2 \mathrm{~mm}$ or more from the pseudobulb epidermis. In longitudinal sections, buds less than $2 \mathrm{~mm}$ only showed a single dome-shaped apical meristem in the center of several layers of leaf primordia embracing it (Fig. 3A). Cells in the apical meristem had dense cytoplasmic contents and chromosomes were condensed. The histological structure corresponded to a vegetative shoot primordium or, perhaps, a reproductive primordium with flower formation already induced but not yet differentiated. Therefore, to investigate flower differentiation, axillary buds were sampled only after they had protruded $2 \mathrm{~mm}$ from the pseudobulb epidermis.

Table 2. Effect of nutrient termination date regardless of nutrient reapplication time on flowering data of Dendrobium Sea Mary 'Snow King'.

\begin{tabular}{lcccc}
\hline $\begin{array}{l}\text { Nutrient } \\
\text { termination } \\
\text { date }\end{array}$ & $\begin{array}{c}\text { Nodes with } \\
\text { flowers } \\
\text { (no.) }\end{array}$ & $\begin{array}{c}\text { Nodes with } \\
\text { aborted } \\
\text { buds (no.) }\end{array}$ & $\begin{array}{c}\text { Total } \\
\text { flowers } \\
\text { (no.) }\end{array}$ & $\begin{array}{c}\text { Avg flowers } \\
\text { per flowering } \\
\text { node } \\
\text { (no.) }\end{array}$ \\
\hline 1 Aug. & $8.5 \mathrm{~b}^{\mathrm{z}}$ & $0.47 \mathrm{a}$ & $24.6 \mathrm{~b}$ & $2.9 \mathrm{~b}$ \\
1 Sept. & $8.3 \mathrm{~b}$ & $0.33 \mathrm{ab}$ & $26.5 \mathrm{~b}$ & $3.2 \mathrm{a}$ \\
1 Oct. & $9.2 \mathrm{a}$ & $0.13 \mathrm{~b}$ & $30.3 \mathrm{a}$ & $3.3 \mathrm{a}$ \\
Significance & $* *$ & $*$ & $* * *$ & $* * *$
\end{tabular}

${ }^{\mathrm{z}}$ Mean separation within columns by Duncan's multiple range test at $P \leq 0.05$.

${ }^{*},{ }^{* *},{ }^{* * *}$ Significant at $P \leq 0.05,0.01$, or 0.001 , respectively. 

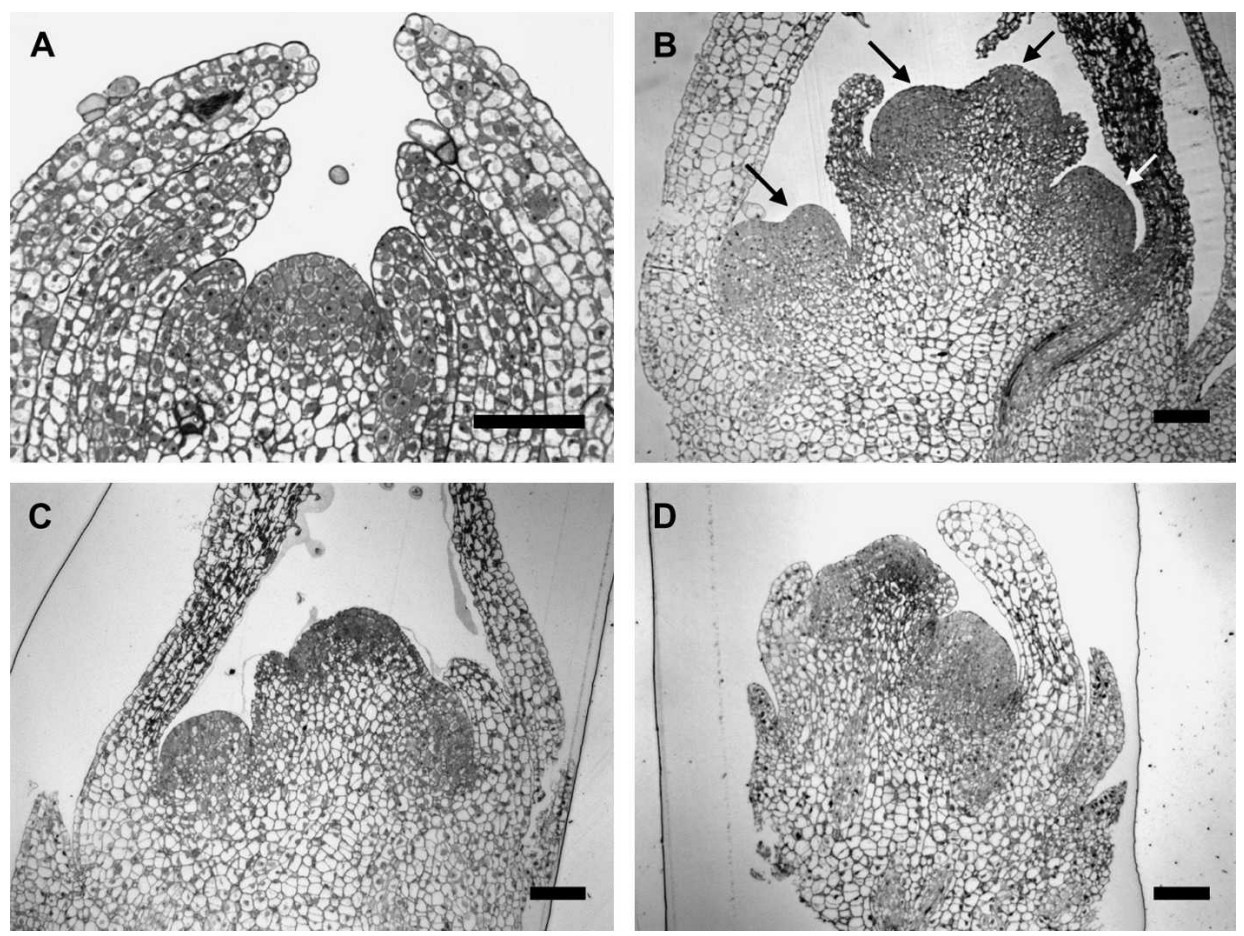

Fig. 3. Longitudinal sections of vegetative apex and differentiated reproductive primordia from Dendrobium Sea Mary 'Snow King' plants with various nutrient termination dates. All buds were sampled when plants had 2-mm protruded buds from pseudobulb epidermis 4 weeks after cooling began. (A) Vegetative apex from a plant in the observational control group without cooling. Nutrient termination dates were (B) 1 Aug., (C) 1 Sept., and (D) 1 Oct. Arrows indicate active meristematic tissues to form individual flowers; bars $=100 \mu \mathrm{m}$.

After 3 weeks at $15{ }^{\circ} \mathrm{C}$, lateral buds had fulfilled their cooling requirement for flower initiation and started to develop and protrude slightly $(\approx 1 \mathrm{~mm})$ from the pseudobulb epidermis before being removed from the cooling treatment. Therefore, after 4 weeks in cooling, at the time which nutrient reapplication times 4 and 5 had not been started, 2-mm protruded lateral buds from the plants in only nine treatments (Table 3 ) and the observational control group were sampled.

All the buds, except for those from the observational control group (Fig. 3A), had entered the reproductive stage with flower primordia differentiated. They contained multiple, less-thanperfect dome-shaped floral meristems that were each embraced by bract primodium (Fig. 3B-D). Actively differentiating tissues in these apices could be easily identified. Cells in these

Table 3. Histological results for axillary buds of Dendrobium Sea Mary 'Snow King' with various nutrient termination dates and reapplication times ${ }^{\mathrm{z}}$.

\begin{tabular}{lcccc}
\hline $\begin{array}{l}\text { Nutrient reapplication } \\
\text { time (relative to cooling) }\end{array}$ & $\begin{array}{c}\text { Date } \\
\text { reapplied }\end{array}$ & 1 Aug. & 1 Sept. & 1 Oct. \\
\hline 1 (beginning) & 13 Nov. 2006 & $\mathrm{R}^{\mathrm{y}}$ & $\mathrm{R}$ & $\mathrm{R}$ \\
2 (middle) & 4 Dec. 2006 & $\mathrm{R}$ & $\mathrm{R}$ & $\mathrm{R}$ \\
3 (immediately after) & 25 Dec. 2006 & $\mathrm{R}$ & $\mathrm{R}$ & $\mathrm{R}$ \\
4 (2 weeks after) & 8 Jan. 2007 & $\mathrm{N} / \mathrm{A}^{\mathrm{x}}$ & $\mathrm{N} / \mathrm{A}$ & $\mathrm{N} / \mathrm{A}$ \\
5 (no reapplication) & & $\mathrm{N} / \mathrm{A}$ & $\mathrm{N} / \mathrm{A}$ & $\mathrm{N} / \mathrm{A}$ \\
\hline
\end{tabular}

${ }^{\mathrm{z} B u d s}$ were sampled on 14 Dec. 2006 when having reached $2 \mathrm{~mm}$.

${ }^{\mathrm{y}}$ Denotes the lateral buds of plants in the treatment were examined and recognized as reproductive primordia.

${ }^{x}$ Denotes the lateral buds were not sampled because plants had not been subjected to different treatments from time 3 . tissues had thin, smooth cell walls and were full of cytoplasm instead of vacuoles, and chromosomes in the nuclei were condensed. The reproductive buds' large histological differences in structure and comparatively larger size than the vegetative apex indicated that they were differentiating flower primordia. For all of the reproductive buds, three to four meristematic zones coexisted and were separated by cells having small cytoplasm and distinguishable vacuoles. The number of vivid cell clusters ranging from three to four in each lateral bud was consistent with the average flower number per flowering node that was observed later in the greenhouse after anthesis (Fig. 3B; Table 2). Thus, it was further verified that the meristematic zones represented individual flowers on a node, and the tissues between the zones developed into bracteoles born at the base of each flower pedicel.

The only noticeable histological difference between nutrient termination date or reapplication time was that plants in the first nutrient termination date, 1 Aug. (Fig. 3B), had larger flower primordia than those ended of nutrients on 1 Oct. (Fig. 3D). Differentiating primordia from 1 Aug. nutrient termination treatment ranged from 550 to $800 \mu \mathrm{m}$ wide in the longitudinal sections, whereas those from the second termination date ranged from 500 to $600 \mu \mathrm{m}$ wide and 300 to $550 \mu \mathrm{m}$ wide from the 1 Oct. termination (data not shown). Although the difference was not drastic, it still implied that flower differentiation started earlier or faster when nutrient supply was ended at an earlier time.

In summary, all the buds examined except for the observational control group were differentiating reproductive primordia after 4 weeks of the inductive cooling treatment, and all the plants except for some plants in the observational control group flowered profusely without producing any aerial shoots. That is to say, no reversion of reproductive to vegetative buds occurred as a result of either late nutrient termination or resumption of nutrient application at the time of cooling.

\section{Discussion}

Ample supply of nutrients during vegetative growth is important not only to producing robust shoots, but also to subsequent flowering in orchids. The emerging vegetative shoots that grow into matured pseudobulbs and the newly differentiated inflorescences are both strong sinks (Hew and $\mathrm{Ng}$, 1996; Wadasinghe and Hew, 1995) that demand large 
amounts of mineral nutrients and photoassimilates for their development. Mineral nutrients from the growing media and fertilization and, often, those stored in other parts of the plant body are the main sources to support the rapid growth of these strong sinks. Research on a nobile dendrobium, Dendrobium Red Emperor 'Prince' (Bichsel, 2006), Dendrobium moschatum Wall. (Bhattacharjee, 1981), and a white-flowered Phalaenopsis hybrid (Phalaenopsis amabilis Blume $\times$ Phalaenopsis Mount Kaala 'Elegance') (Wang and Gregg, 1994) showed that adequate rates of nutrient supply promoted vegetative growth and thereby enhanced the subsequent flowering performance, including taller plants with more nodes or leaves, increased flower counts or size, or a faster growth rate of inflorescences. Although in the current study, nutrient supply varied by application durations rather than nutrient rates, increasing duration of nutrient application resulted in improved growth and flowering.

In this experiment, improved growth and flowering were expected by either a later nutrient termination date or an earlier reapplication time that provided higher availability of nutrients to the plants. However, vegetative growth and flowering were unaffected by reapplication time. The data suggest that flower development benefited more from the nutrients that were accumulated in mature pseudobulbs during growth and maturation rather than from those being taken from the added fertilizers while approaching flowering. Remobilization of nutrients and photoassimilates from pseudobulbs for inflorescences development has been reported for the Goldiana hybrid of Oncidium Sw. (Hew and Ng, 1996; Yong and Hew, 1995). By monitoring changes of dry matter and total mineral contents in various plant parts, it was found that part of the minerals and carbohydrates accumulated in mature pseudobulbs was later allocated to developing inflorescences and axillary buds. The active accumulation of mineral nutrients and carbohydrates during pseudobulb development constituted an important source of reserves for the subsequent development of inflorescences and new shoots for Oncidium Goldiana (Hew and $\mathrm{Ng}$, 1996). As a result, to obtain a high flowering capacity with optimum quality in nobile dendrobiums, nutrient supply should not be ended until the current year's pseudobulbs have swollen and matured to establish robust plants (i.e., long pseudobulbs with a high node number and high leaf retention).

Properly extended nutrient supply before being ended has been shown to benefit orchid production. Wang (2000) found that discontinuing fertilization before late November caused reduced flower count and loss of lower leaves in Phalaenopsis TAM Butterfly. For Dendrobium Red Emperor 'Prince,' a nobile dendrobium, ending nutrients on 1 Oct. rather than earlier or later was recommended because plants produced more flowers without adverse effects on flowering such as reduced flower size and delayed anthesis that were caused by 1 Nov. nutrient termination (Bichsel, 2006). In the current study, termination of nutrients on 1 Oct. resulted in the highest leaf retention and flower count and the fewest aborted floral buds among treatments. The results suggest that termination of nutrients at an appropriate timing in the fall is beneficial to growth, and the nutrients accumulated in mature pseudobulbs support subsequent flowering of nobile dendrobiums. The suggestions by Wood (2006) and Yamamoto Dendrobiums (2007) to end nutrient application as early as August without giving specific information on developmental stage of the plants or cultivation latitude are thus questionable.
Slight delay in full flowering is beneficial to growers and consumers because plants have a better postharvest quality and robustness because unopened flowers are less prone to shipping damage. In this study, termination of nutrient supply on 1 Oct. delayed the time required to reach full flowering for $1.5 \mathrm{~d}$ compared with being ended on 1 Aug., indicating that growers should end the nutrient supply on 1 Oct. to ensure better plant quality. In addition, flowering pot plants are purchased by consumers who prefer to purchase orchids before they reach full flowering, so the delay in full flowering would allow consumers to have an extended time to enjoy the process of flowering.

However, adequate early nutrient termination may help to program flowering for a specific market time. From histological observation in this experiment, the sizes of the floral primordia implied that earlier termination of nutrient supply resulted in earlier pseudobulb maturation, so flower differentiation began earlier or faster. Therefore, when nutrient supply is ended earlier, the plants with mature pseudobulbs may be subjected to low temperature induction and forced to flower at an earlier time.

Improvement in leaf retention by properly extended nutrient application may benefit orchid production, especially for the nobile dendrobiums. Consumers prefer nobile dendrobiums with green leaves attached rather than those without foliage at the time of flowering. However, low temperatures for flower initiation often cause the leaves to turn yellow and abscise. Consequently, in nature, inflorescences of several Dendrobium species develop on defoliated pseudobulbs (Wang, 1999; Wood, 2006).

Optimal nutrient supply during production serves to prevent the undesirable leaf abscission. When nutrient supply is restrained, leaves are prone to be affected by nutrient deficiency. Dendrobium phalaenopsis Fitzg. was severely affected by the omission of $\mathrm{N}, \mathrm{P}, \mathrm{K}$, calcium, or magnesium in the nutrient solution and leaf abscission occurred before deficiency symptoms appeared (Hew and Yong, 2004). Bichsel (2006) found that without N supply, leaf loss in Dendrobium Red Emperor 'Prince' was greater, having only $38 \%$ leaf retention, compared with those supplied with N. For Phalaenopsis TAM Butterfly, plants with the earlier nutrient termination dates (1 Sept., 29 Sept., and 27 Oct. as compared with the later 24 Nov. or continuous fertilization) had fewer leaves, mainly as a result of abscission of lower leaves (Wang, 2000). K-deficient Phalaenopsis plants started to lose their leaves when plants were becoming reproductive (Wang, 2007). In the current study, plants supplied with nutrients until 1 Oct. had significantly higher leaf retention than those with the earlier nutrient termination dates. Therefore, sufficient nutrient duration to support vegetative growth and flowering seems crucial for leaf retention in orchids.

Histological studies in nobile dendrobiums with detailed methods and thorough observations are lacking. In this study, a histological protocol that accelerated tissue processing by microwave assistance and prepared exquisite microscopic images was developed. The protocol allowed excellent structural preservation, and the formulation of the resin mixture provided good sectioning quality. For the first time in nobile dendrobiums, it was found that lateral buds at or above size $2 \mathrm{~mm}$ protruding the pseudobulb epidermis showed distinguishable floral primordia under a microscope, thus facilitating the investigation of bud reversion.

It was suspected that factors favoring vegetative growth of the nobile dendrobiums might trigger the reversion of floral primordia to vegetative shoots. In nobile dendrobiums, it has 
been speculated that extended nutrient supply, which is in favor of vigorous vegetative growth, might cause aerial shoot formation and perhaps even trigger floral primordia to revert to vegetative primordia. However, in this study, no aerial shoots formed despite nutrient termination date as late as 1 Oct. or nutrient reapplication that spanned an 8 -week time period from time 1 to 4 . Bichsel et al. (2008) also showed that, with proper cooling, applying nutrients continuously until flowering resulted in no aerial shoot formation in Dendrobium Red Emperor 'Prince'. Therefore, it is possible that the formation of aerial shoots on the observational control group in this experiment was the result of lack of adequate cooling. In two nobile dendrobium cultivars, Dendrobium Snowflake 'Red Star' and Dendrobium Hinode 'Toutenkou', although the actual reversion from an initiated floral bud to a vegetative shoot was not observed, exposure to a high day temperature of $30^{\circ} \mathrm{C}$ for $2 \mathrm{~h}$ daily for $40 \mathrm{~d}$ during the cooling period at $20^{\circ} \mathrm{C}$ promoted aerial shoot formation (Sinoda et al., 1988).

In conclusion, to produce quality 2 -year-old flowering pot nobile dendrobiums, plants should be grown with ample nutrient supply during vegetative growth until pseudobulb maturation. Prolonged nutrient supply until 1 Oct. helps to establish robust plants with high leaf retention and to accumulate enough reserves in the mature pseudobulbs for subsequent flower development. Nutrient reapplication during or after cooling is not needed for quality flowering.

\section{Literature Cited}

Abramoff, M.D., P.J. Magelhaes, and S.J. Ram. 2004. Image processing with ImageJ. Biophotonics Intl. 11:36-42.

Arnold Bik, R. and T.J.M. van den Berg. 1983. Effect of substrate and nitrogen supply on yield and quality of mini-Cymbidium. Acta Hort. 150:289-295.

Baker, M.L. and C.O. Baker. 1996. Orchid species culture: Dendrobium. Timber Press, Portland, OR.

Bhattacharjee, S.K. 1981. The effects of nitrogen, phosphorus, and potassium on growth and flowering of Dendrobium moschatum Wall. Gartenbauwissenschaft 46:176-181.

Bichsel, R.G. 2006. Determining the nutritional requirements for optimizing flowering of the nobile dendrobium as a potted orchid. Texas A\&M Univ., College Station. MS Thesis.

Bichsel, R.G., T.W. Starman, and Y.T. Wang. 2008. Nitrogen, phosphorus, and potassium requirements for optimizing growth and flowering of the nobile dendrobium as a potted orchid. HortScience 43:328-332.
Hew, C.S. and C.K.Y. Ng. 1996. Changes in mineral and carbohydrate content in pseudobulbs of the $\mathrm{C}_{3}$ epiphytic orchid hybrid Oncidium Goldiana at different growth stages. Lindleyana 11:125-134.

Hew, C.S. and J.W.H. Yong. 2004. The physiology of tropical orchids in relation to the industry. 2nd Ed. World Scientific, Singapore.

Ichihashi, S. 1997. Orchid production and research in Japan, p. 171212. In: Arditti, J. and A.M. Pridgeon (eds.). Orchid biology: Reviews and perspectives, VII. Kluwer Academic Publishers, Dordrecht, The Netherlands.

Laws, N. 2004. The world's fascination with potted orchids. FloraCulture Intl. 14:26-27.

Rotor G.B., Jr. 1952. Daylength and temperature in relation to growth and flowering of orchids. Cornell Expt. Sta. Bul. 885.

Rotor G.B., Jr. 1959. The photoperiodic and temperature response of orchids, p. 397-417. In: Withner, C.L. (ed.). The orchids, a scientific survey. Ronald Press, New York, NY.

Sinoda, K., K. Suto, M. Hara, and M. Aoki. 1988. Effect of day and night temperature on the flowering of Dendrobium nobile-type cultivars [in Japanese]. Bul. Natl. Res. Inst. Veg. Ornamental Plants Tea, Ser. A. 2:279-290.

U.S. Department of Agriculture. 2006. Floriculture crops 2005 summary. U.S. Dept. Agr., Washington, DC.

U.S. Department of Agriculture. 2007. Floriculture crops 2006 summary. U.S. Dept. Agr., Washington, DC.

Wadasinghe, G. and C.S. Hew. 1995. The importance of back shoots as a source of photoassimilates for growth and flower production in Dendrobium cv. Jashika Pink (Orchidaceae). J. Hort. Sci. 70:207214.

Wang, Y.T. 1999. Dendrobium anosmum —Everyone should have one. Orchids 68:1026-1028.

Wang, Y.T. 2000. Impact of a high phosphorus fertilizer and timing of termination of fertilization on flowering of a hybrid moth orchid. HortScience 35:60-62.

Wang, Y.T. 2004. Flourishing market for potted orchids. FlowerTech 7:2-5.

Wang, Y.T. 2007. Potassium nutrition affects phalaenopsis growth and flowering. HortScience 42:1563-1567.

Wang, Y.T. and L.L. Gregg. 1994. Medium and fertilizer affect the performance of Phalaenopsis orchids during two flowering cycles. HortScience 29:269-271.

Wood, H.P. 2006. The dendrobiums. A.R.G. Gantner Verlag, Ruggell, Liechtenstein.

Yamamoto Dendrobiums. 2007. Caring. 20 Sept. 2007. <http://www. yamamotodendrobiums.com>.

Yong, J.W.H. and C.S. Hew. 1995. The importance of photoassimilate contribution from the current shoot and connected back shoots to inflorescence size in the thin-leaved sympodial orchid Oncidium Goldiana. Intl. J. Plant Sci. 156:450-459. 